\title{
Prevalence of excess weight gain and associated risk factors among postmenopausal women: a population-based study in Ghana.
}

Isaac Mensah Bonsu ( $\sim$ piceabc@yahoo.com )

University of the Witwatersrand Faculty of Health Sciences https://orcid.org/0000-0002-6750-3855

Hellen Myezwa

University of the Witwatersrand Faculty of Health Sciences

Corlia Brandt

University of the Witwatersrand Faculty of Health Sciences

Moses M. Omoniyi

Kwame Nkrumah University of Science and Technology College of Health Sciences

Tunde A. Ajidahun

University of the Witwatersrand Faculty of Health Sciences

Research article

Keywords: Postmenopausal, Body mass index, Waist-to-hip ratio, Waist-to-height ratio, Obesity, Desirable weight/

Posted Date: January 19th, 2021

DOl: https://doi.org/10.21203/rs.3.rs-30002/v2

License: (9) (1) This work is licensed under a Creative Commons Attribution 4.0 International License.

Read Full License 


\title{
Prevalence of excess weight gain and associated risk factors among postmenopausal women: a population-based study in Ghana.
}

\author{
Isaac Mensah Bonsu' ${ }^{1}$, Hellen Myezwa ${ }^{1}$, Corlia Brandt ${ }^{1}$, Monday Omoniyi Moses ${ }^{2}$ and \\ Tunde Ajidahun ${ }^{1}$ \\ 1. School of Therapeutic Sciences, Department of physiotherapy, University of The Witwatersrand, Johannesburg, \\ South Africa \\ 2.College of Health Sciences, Faculty of Allied Health Sciences, Department of Physiotherapy and Sports Science, \\ Kwame Nkrumah University of Science and Technology, Kumasi, Ghana
}

Corresponding author; Isaac Mensah Bonsu, piceabc@yahoo.com

Email addresses

IMB; piceabc@yahoo.com

HM: hellen.myezwa@wits.ac.za

CB: corlia.brandt@wits.ac.za

MOM: momoses@knust.edu.gh

TA: tuned.ajidahun@wits.ac.za

\begin{abstract}
Background: Excess weight (obesity and overweight) is a pervasive condition that is considered a global epidemic and a threat to public health. Furthermore, numerous changes in fat deposits occur with the advent of menopause, leading to a change in the distribution of body fat. Therefore this study determined the prevalence of excess weight gain and associated risk factors among postmenopausal women (PW) in Ghana.
\end{abstract}

Methods: This is a descriptive cross-sectional study conducted over five months at Bono-East regional capital, Techiman in Ghana. A total of 378 postmenopausal women were recruited for this study. Structured questionnaires were administered to obtain the socio-demographic data from each study participant. Anthropometrics such as body mass index (BMI), waist-to- 
hip ratio (WHR) and waist-to-height ratio (WHtR) among participants were also determined. Data were inputted into excel, and analysis was done using IBM SPSS 25.

Results: BMI, WHtR and WHR recorded participants with the excess weight of $73.2 \%, 91.8 \%$, and $91.0 \%$ respectively out of the total study participants and there was no significant difference among the stratified study participants. Participants age $\leq 50$ years were at a high risk of been obese even though it was not significant. Study participants with $>15$ years of the postmenopausal stage have a high chance of been obese for BMI and WHtR but not WHR. The mean age of study participants was $60.09 \pm 6.24$ years with the 51-60 years age group having the highest frequency $(48.8 \%)$. Out of the total study participants, $26.8 \%, 8.2 \%$ and $9.0 \%$ with desirable weight were recorded using BMI, WHtR, and WHR respectively. And there was no significant difference $(\mathrm{P}=0.999)$ between the proportions for WHtR and WHR. However, the distribution of study participants with desirable weight by BMI was significantly higher than that of WHtR $(\mathrm{P}=0.0031)$ and WHR $(\mathrm{P}=0.0063)$.

Conclusions: The prevalence rates of obesity and overweight were higher among postmenopausal women using the WHR than BMI and WHtR. Participants age $\leq 50$ years, parity and those from the Ga tribe were also at a higher risk of having abdominal obesity.

Keyword: Postmenopausal, Body mass index, Waist-to-hip ratio, Waist-to-height ratio, Obesity, Desirable weight/

\section{Background}

Excess weight (obesity and overweight) is one of the most significant contributors to poor health (Teede et al., 2010), exceeding both undernutrition and infectious diseases (Lau et al., 2007). The prevalence of obesity has increased worldwide over the past 50 years (Blüher, 2019) and the incidence of excess body weight among women has attained epidemic 
proportions globally (Wang et al., 2007). The arrival of the menopause in middle-age is associated with a tendency to gain weight (Dubnov-Raz et al., 2007; Flegal et al., 2010). It is estimated that the prevalence of women aged 40-59 (42.1\%) in United State has higher prevalence of obesity than women aged 20-39 (34.4\%) (States, Flegal, \& Ph, 2015). In Ghana, a survey by Agbeko et al., (2013) indicated that the pattern of overweight and obesity appeared to be positively associated with age ranging from $14 \%$ for women aged 1524 to $43 \%$ for those aged $35-44$.

Obesity and overweight are the result of the interplay between heterogenic factors, deriving from a person's eating behavior, physical activity and individual energy expenditure determinants (Blüher, 2019). Furthermore, numerous changes in fat deposits occur with the advent of menopause, leading to a change in the distribution of body fat across the body. The negative effect of hypoestrogenism on fat metabolism results in central body obesity (Douchi et al., 2003; Sowers et al., 2007). The North American Menopause Society (2012) states that ageing, lifestyle, and behavioural factors, such as a lack of exercise and an increase in food consumption, are closely linked with weight gain in menopause (NAMS, 2012). Several studies have been conducted in an attempt to characterize the factors associated with weight gain in menopause ( Cuadros et al., 2011; Lizcano and Guzmán, 2014); however, there are few published population-based studies which have evaluated the demographical factors associated with the prevalence of obesity and overweight in postmenopausal women especially in the subSaharan African region like Ghana.

Obesity represents a significant major health challenge that substantially increases the risk of cardiovascular diseases, dementia, osteoarthritis, obstructive sleep apnoea, and several cancers, thereby contributing to a decline in both quality of life and life expectancy (Ikram et al., 2017). Obesity is also associated with unemployment, social disadvantages, and reduced socioeconomic productivity, thus increasingly creating an economic burden (Blüher, 2019). 
Reducing the burden of excess weight gain requires multiple approaches that combine individual interventions with changes in the environment and society (Gortmaker et al., 2011). Therefore, a better understanding of the regional differences in the prevalence and trends of obesity might help to identify societal causes of obesity and provide guidance on which are the most promising intervention strategies. Against this background, this study sought to determine the prevalence of excess weight gain and associated risk factors among postmenopausal women in Ghana.

\section{Methods}

\section{Study site and design}

A descriptive cross-sectional study was conducted for a period of five months from October 2019 to February 2020 at Bono-East regional capital, Techiman in Ghana.

\section{Sampling population}

The study population was selected by stratifying the nation (Ghana) into three geopolitical zones: northern, middle and southern zones. Sequentially, a zone, region and district was selected by simple random sampling. Hospitals, women fellowships, women organizations, churches and mosques were selected randomly from the district and the study participants were recruited through public service invitation. The sample frame comprised of postmenopausal women in Ghana, aged 45 years or older using the 2010 population and housing census in Ghana (GSS, 2010). A sample size of 358 was estimated using the sample size formula for cross-sectional studies in an unknown population (Charan, J. and Biswas, T., 2013). Including a $10 \%$ fall out rate the final sample size was 378 . The calculation was based 
on the prevalence of obesity among post-menopausal women in Ghana $(37.1 \%, \mathrm{p}=0.37)$, (Benkeser, 2012), a margin of error set at 0.05 and a $95 \%$ confidence interval.

Sample size formula for cross-sectional studies: $\frac{\left(\frac{Z}{2}\right)^{2} P(1-P)}{d^{\wedge} 2}$

\section{Inclusion and exclusion criteria}

Postmenopausal Ghanaian women, aged older than 45 years, not on any weight management therapy, not living with any physical or mental disability were included in the study. Women outside the age bracket, not a Ghanaian and who has not lived in Ghana for the past three years were excluded.

\section{Data collection}

\section{Questionnaire}

Demographic information such as age, educational background, marital status, religion, ethnic origin and parity were obtained through self-administered questionnaire

\section{Weight, height and body mass index measurement}

Using standardized methods, body weight and height (to the nearest $0.5 \mathrm{~kg}$ and $0.5 \mathrm{~cm}$, (respectively) were measured using an analogue balance (SECA) and stadiometer. The participants' posture was standardised, ensuring key postural points were consistently positioned namely, with the back against the board and heels touching the base of the vertical board; the feet separated, the knees touching and the buttocks, scapulae, and head positioned in contact with the vertical backboard. The participant`s arms hang freely by the sides of the trunk with palms facing the thighs. Body mass index was assessed as the ratio of body weight to height squared. Using the WHO criteria for Body mass index, BMI was defined as BMI $<18.5 \mathrm{~kg} / \mathrm{m}^{\wedge} 2$ underweight; BMI 18.5 - 24.9kg/m^2 normal weight; BMI 25.0 - 
$29.9 \mathrm{~kg} / \mathrm{m}^{\wedge} 2$ overweight; and $>30.0 \mathrm{~kg} / \mathrm{m}^{\wedge} 2$ obese (WHO, 1998). Excess weight category refers to all those with a $\mathrm{BMI}>25.0 \mathrm{~kg} / \mathrm{m}^{\wedge} 2$

Waist circumference, hip circumference, waist-to-hip ratio, and waist-to-height ratio measurement

Waist circumference (WC) (to the nearest $0.1 \mathrm{~cm}$ ) was measured with the participant in a standing position (with feet together) as the minimum girth around the waist which in some individuals could correspond to the abdominal girth. This was measured with the aid of an inelastic tape measure (Mc Ardle et al., 2000). Hip circumference (to the nearest $0.1 \mathrm{~cm}$ ) was also measured as described for WC above. However, the elastic measuring tape was placed at the region of maximum girth around the buttock - (the trochanteric region) (Mc Ardle et al., 2000). The ratio of waist circumference to that of hip circumference was evaluated as the waisthip ratio in equation one and the waist-to-height ratio calculated in equation two;

Waist-to-hip ratio $=\frac{\text { Waist circumference }(\mathrm{cm})}{\text { Hip circumference }(\mathrm{cm})} \ldots \ldots \ldots \ldots . . .($ Equation 1$)$

Waist-to-height ratio $=\frac{\text { Waist circumference }(\mathrm{cm})}{\text { Height circumference }(\mathrm{cm})} \ldots \ldots \ldots \ldots \ldots \ldots($ Equation 2$)$

Abdominal obesity (WHR) was defined by WC $>88 \mathrm{~cm}$ and WHR $>0.8 \mathrm{~cm}$ (Fouque D et al, 2007) while WHtR was classified as normal: < 0.4, overweight: $0.4-0.5$, obese: $0.5-0.6$, and morbidly obese: > 0.6 (Ashwell M et al, 2012; Dalton M et al 2003)

\section{Data Analysis}

The data collected were screened and coded were necessary before entry using Microsoft Excel spreadsheets. The data set was cross-checked against the hard copies. Data analysis was performed using IBM SPSS for Windows (version 25.0). All variables were summarized using descriptive statistics of frequencies, percentages, means and standard deviation. K-test was used to determine the differences between proportions. Multivariate logistic regression was 
used to assess the association between demographics and the various indexes of weight gain.

Statistical significance was accepted at $\mathrm{p}<0.05$ for all comparisons.

\section{Results}

The age range of the three hundred and seventy-eight (378) postmenopausal women enrolled in this study was from 45 to 80 years with a mean age of $60.09 \pm 6.24$ years. The sociodemographic characteristics of the participants showed that majority of the participants were Christians $(52.2 \%)$, widowed (41.5\%), had at least primary school certificate $(40.4 \%)$, from the Akan tribe (42.7\%) and had between 4-7 children (59.6\%) (Table 1).

Table 1: Distribution of Demographic Data

\section{$S D=$ Standard deviation}

\begin{tabular}{|c|c|}
\hline Demographics & \\
\hline Age in years, Mean (SD) & $60.09(6.24)$ \\
\hline \multicolumn{2}{|l|}{ Age group (years), n (\%) } \\
\hline$\geq 50$ & $24(6.5)$ \\
\hline $51-60$ & $180(48.8)$ \\
\hline $61-70$ & $150(40.7)$ \\
\hline$>70$ & $15(4.2)$ \\
\hline \multicolumn{2}{|l|}{ Religion, n (\%) } \\
\hline Christian & $192(52.2)$ \\
\hline Muslim & $151(41)$ \\
\hline Others & $25(6.8)$ \\
\hline \multicolumn{2}{|l|}{ Marital Status, n (\%) } \\
\hline Married & $130(35.2)$ \\
\hline Widow & $153(41.5)$ \\
\hline Single & $34(9.2)$ \\
\hline Divorce & $52(14.1)$ \\
\hline \multicolumn{2}{|l|}{ Ethnic origin, n ( $\%)$} \\
\hline Northerner & $137(37.4)$ \\
\hline Akan & $148(40.4)$ \\
\hline $\mathrm{Ga}$ & $42(11.5)$ \\
\hline Voltarian & $34(9.3)$ \\
\hline Others & $5(1.4)$ \\
\hline \multicolumn{2}{|l|}{ Educational background, n (\%) } \\
\hline Primary & $155(42.7)$ \\
\hline High School & $97(26.7)$ \\
\hline Tertiary & $68(18.8)$ \\
\hline Others & $43(11.8)$ \\
\hline Parity, n (\%) & \\
\hline
\end{tabular}




\begin{tabular}{|c|c|}
\hline$<3$ & $41(14)$ \\
\hline $4-7$ & $174(59.6)$ \\
\hline$>7$ & $77(26.4)$ \\
\hline
\end{tabular}

Prevalence of excess weight gain 

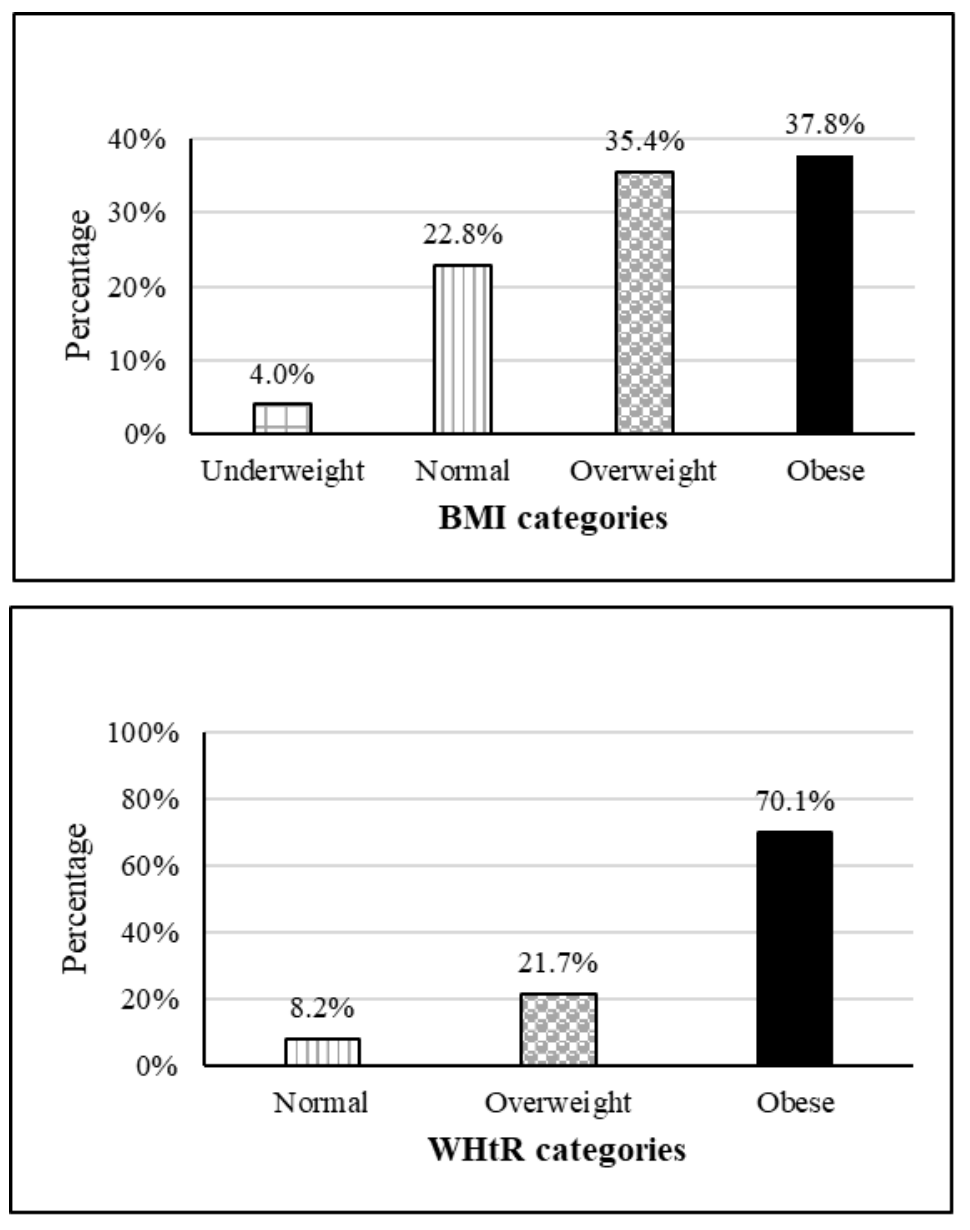

B

C

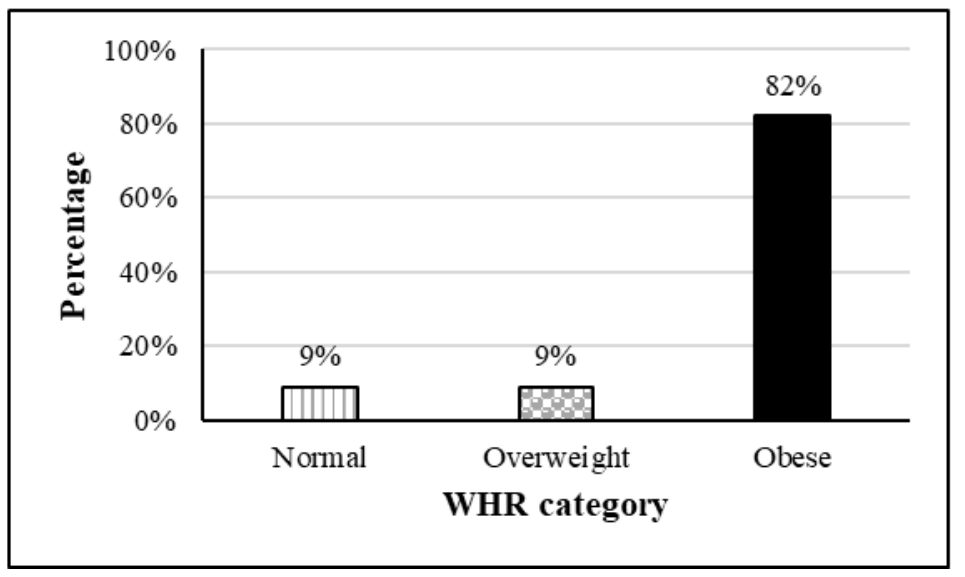

Figure 1: Prevalence of excess weight gain among study participants stratified by; A) body mass index categories, B) waist-to-height ratio categories, C) waist-to-hip ratio categories.

Using the WHO cut-offs as reference, $37.8 \%$ of the participants were obese, $35.4 \%$ overweight, $22.8 \%$ normal weight and $4.0 \%$ underweight (Figure 1a). The results in Figure 1b indicate, $70.1 \%$ were obese and $8.2 \%$ had normal waist to height ratio. According to the waist to hip 
ratio, $82.0 \%$ were obese and $9.0 \%$ overweight (Figure 1c). Excess weight is define using overweight and obese across the three indices (BMI, WHR and WHtR) and the desirable weight are those who are normal according to the three parameters
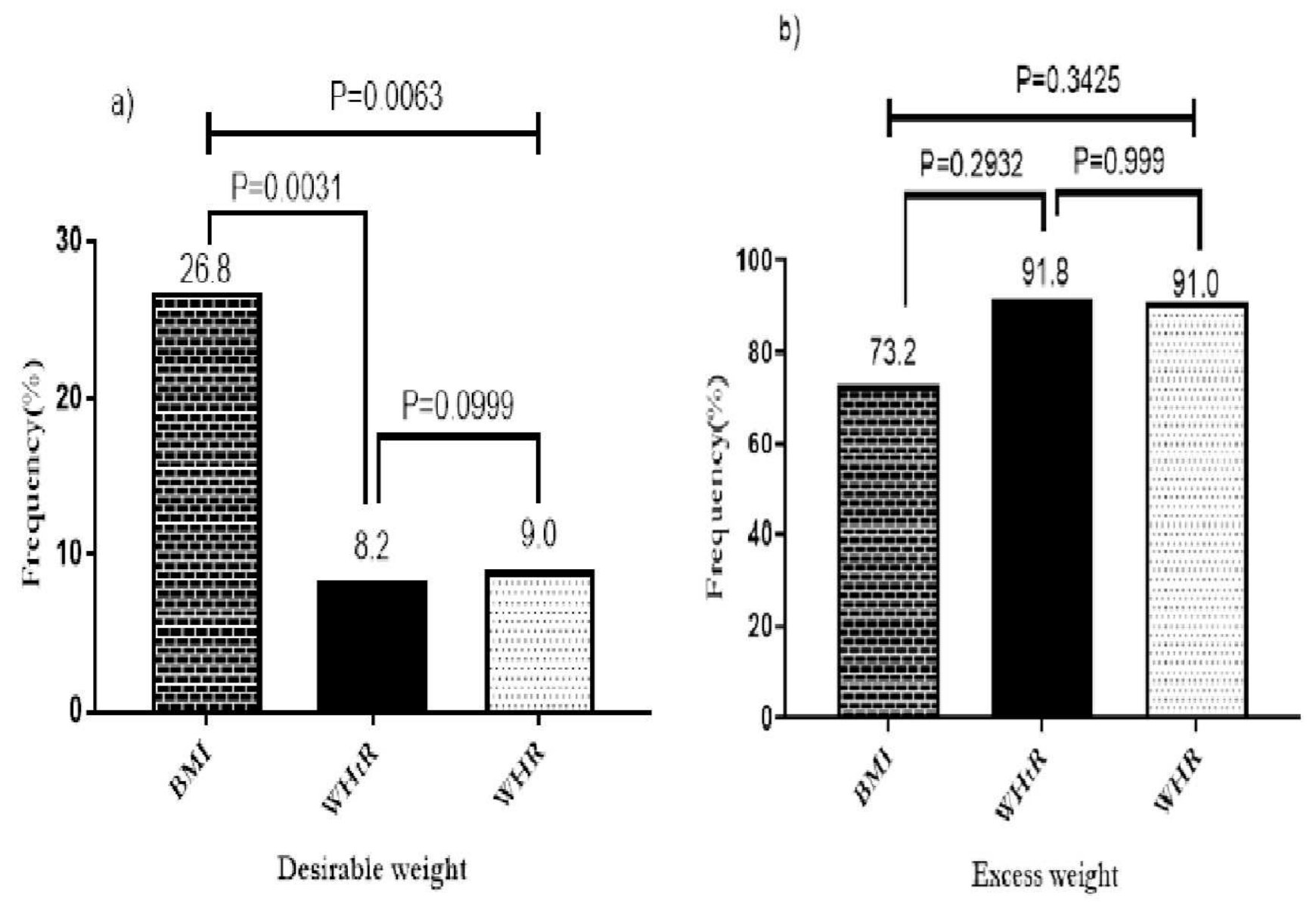

Figure 2: Distribution of body mass index, waist-to-height ratio, and waist-to-hip ratio by desirable and excess weight.

According to the findings from the BMI, WHtR, and WHR respectively, $26.8 \%, 8.2 \%$ and 9.0\% of the sample had a desirable weight although there was no significant difference $(\mathrm{P}=0.999)$ between the proportion of study participants with a desirable weight for WHtR and WHR (Figure 2a). The distribution of study participants with desirable weight categorised by BMI was significantly higher than that of WHtR $(\mathrm{P}=0.0031)$ and WHR $(\mathrm{P}=0.0063)$. Using BMI, WHtR and WHR, 73.2\%, 91.8\%, and 91.0\% of participants had excess weight 
respectively. There was no significant difference among study participants with excess weight calculated by BMI, WHtR and WHR (Figure 2b).

Table 2 depicts multivariate binary logistic regression analysis predicting the odds ratio for demographic risk factors for obesity among study participants. For all the anthropometric measurements, participants' $\leq 50$ years were at a high risk of being obese, however it was not significant. Study participants who exceeded more than 15 years of the postmenopausal stage had a high chance of being obese according to their BMI and WHtR but not WHR. BMI and WHR show that postmenopausal women of the Ga tribe were at a higher risk of being obese. Participants who had more than 7 children were at a higher risk of excess weight gain.

Table 2: Multivariate binary logistic regression analysis predicting the odds ratio for demographic risk factors for obesity among study participants.

\begin{tabular}{|c|c|c|c|}
\hline Demographics & $\begin{array}{l}\text { BMI-Obesity } \\
\text { aOR }(95 \% \mathrm{CI})\end{array}$ & $\begin{array}{l}\text { WHR-Obesity } \\
\text { aOR (95\% CI) }\end{array}$ & $\begin{array}{l}\text { WHTR-Obesity } \\
\text { aOR }(95 \% \mathrm{CI})\end{array}$ \\
\hline \multicolumn{4}{|l|}{ Age group (years) } \\
\hline$\leq 50$ & 1 & 1 & 1 \\
\hline $51-60$ & $0.4(0.1-2.0)$ & - & $0.6(0.1-3.3)$ \\
\hline $61-70$ & $0.3(0.1-1.9)$ & - & $0.5(0.1-3.3)$ \\
\hline$>70$ & - & $0.8(0.2-1.6)$ & $0.2(0.0-7.2)$ \\
\hline \multicolumn{4}{|l|}{ Religion } \\
\hline Christian & 1 & 1 & 1 \\
\hline Muslim & $1.8(0.8-4.3)$ & $0.9(0.2-3.0)$ & $1.1(0.5-2.7)$ \\
\hline Others & - & $0.2(0.0-1.7)$ & $1.1(0.2-6.9)$ \\
\hline \multicolumn{4}{|l|}{ Marital } \\
\hline Married & 1 & 1 & 1 \\
\hline Widow & $1.1(0.4-2.8)$ & $1.1(0.3-3.7)$ & $1.4(0.6-3.4)$ \\
\hline Single & $1.1(0.2-5.0)$ & $3.5(0.4-32.7)$ & $0.7(0.2-2.9)$ \\
\hline Divorce & $2.3(0.7-7.5)$ & $2.5(0.4-15.5)$ & $2.7(0.7-10.7)$ \\
\hline \multicolumn{4}{|l|}{ Ethic origin } \\
\hline Northerner & 1 & 1 & 1 \\
\hline Akan & $1.4(0.6-3.6)$ & $0.1(0.0-0.7)^{*}$ & $3.2(1.2-8.51)$ \\
\hline $\mathrm{Ga}$ & $3.1(0.8-12.4)$ & $4.7(1.1-20.6)^{*}$ & $2.0(0.5-7.9)$ \\
\hline Voltarian & $1.0(0.2-4.6)$ & $0.6(0.1-4.4)$ & $1.2(0.3-4.8)$ \\
\hline \multicolumn{4}{|l|}{ Others } \\
\hline \multicolumn{4}{|l|}{$\begin{array}{l}\text { Educational } \\
\text { background }\end{array}$} \\
\hline Primary & 1 & 1 & 1 \\
\hline High School & $0.8(0.3-1.8)$ & $8.6(2.0-36.9)^{*}$ & $1.3(0.5-3.2)$ \\
\hline
\end{tabular}




\begin{tabular}{lccc} 
Tertiary & $0.4(0.1-1.3)$ & $1.0(0.3-2.7)^{*}$ & $1.8(0.5-6.1)$ \\
Others & $0.1(0.0-0.6)$ & $1.9(0.4-8.9)$ & $1.2(0.4-4.0)$ \\
Parity & & & \\
$<3$ & 1 & 1 & 1 \\
$4-7$ & $0.8(0.3-2.0)$ & $0.2(0.0-0.9)^{*}$ & $0.8(0.3-2.2)$ \\
$>7$ & $1.5(0.4-5.5)$ & $0.5(0.1-3.5)$ & $1.9(0.5-7.7)$ \\
Postmenopausal stage (years) & & \\
$\leq 5$ & 1 & 1 & 1 \\
6-10 & $1.0(0.4-2.4)$ & $0.7(0.2-2.4)$ & $0.8(0.3-2.0)$ \\
$11-15$ & $0.9(0.2-5.1)$ & $0.5(0.1-3.2)$ & $0.9(0.2-5.2)$ \\
$>15$ & $4.0(0.3-61.0)$ & $0.2(0-4.4)$ & $1.5(0.1-23.1)$ \\
\hline *P-value $<0.05=$ statistically significant, aOR=Adjusted Odds Ratio. CI=Confidence Interval
\end{tabular}

\section{Discussion}

The study revealed a high prevalence rate of excess weight of $73.2 \%, 91.8 \%$, and $91.0 \%$ using BMI, WHtR and WHR respectively among the participants. There was no substantial difference among the stratified study participants. Participants age $\leq 50$ years were at a high risk of been obese even though it was not significant. Participants with > 15 years of the postmenopausal stage have a high chance of been obese for BMI and WHtR but not WHR. Participants age $\leq 50$ years, parity and those from the Ga tribe were also at a higher risk of having abdominal obesity.

Menopause is usually a cause of many concerns among women (Graziottin, 2010). One of the most important is the fear of weight gain. It is well known that obesity and metabolic syndrome are found in women in this period of their life three times more often than before menopause (Kozakowski et al., 2017).

High prevalence rates of obesity and excess weight gain were observed among participants. From this study, $37.8 \%$ of the participants were obese, followed by overweight $(35.4 \%)$, normal $(22.8 \%)$ and underweight (4.0\%) according to the body mass index (BMI). A study by Gravena et al. (2013) on excess weight and abdominal obesity in postmenopausal Brazilian women reported a similar prevalence rate for obesity (35.5\%) using BMI. In addition, 63.6\% of abdominal obesity was observed in the same study using waist circumference (Gravena et 
al., 2013). However, the prevalence rate of overweight (72.6\%) they recorded was higher than that of this study which may be driven by age difference as the mean age was $58.7 \pm 5.7$ years compared to $60.09 \pm 6.24$ years for this study. Furthermore, a longitudinal 9-year study with 949 participants in the Study of Women's Health Across the Nation (SWAN) investigated the natural history of the menopausal transition and showed that waist circumference(WC) increased with aging and accelerated after the menopause (Manuscript, 2010). Stevens et al., (2010) further explained that WC and waist-to-hip ratio (WHR) are influenced by body weight, body composition and fat distribution and had associations and increases with age. This phenomenon may be due to the hormonal influences in their bodies and behavioural factors that contribute to their excess weight gain (Frisch, 2007; Douchi et al., 2003; Sowers et al., 2007)

Findings on WHR showed that, $82.0 \%$ participants were obese, $9.0 \%$ overweight and $9.0 \%$ normal respectively. Also, $70.1 \%$ were obese and $8.2 \%$ normal according to the WHtR. This trend has been established in similar populations elsewhere (Arthur et al. 2013) among postmenopausal Ghanaian women which revealed that $5.6 \%$ were overweight and $93.5 \%$ obese using WHR. Additionally, $19.8 \%$ of women in Arthur et al's study were normal, and $83.2 \%$ were obese using the WHtR (Arthur et al., 2013). Although the prevalence rates recorded by Arthur et al. (2013) were higher than this study, there are positive congruence between the two studies which could imply that WHR is perhaps appropriate anthropometric index to assess obesity among women (Cao et al., 2018). Moreover, Kissebah and Krakower, (1994) also established that WHR provides useful indices of abdominal fat accumulation and provides a better correlation with an increased risk of ill health than BMI alone. The WHO further echoes this point that BMI can be used to estimate the prevalence of obesity within a population but cannot account for the wide variation in body fat distribution (WHO, 2005). 
An interesting finding was that, there was no significant difference between the proportions for WHtR and WHR with a desirable weight gain. However, the distribution of study participants with desirable weight according to their BMI was significantly higher than that of WHtR and WHR. BMI, WHtR and WHR recorded percentages of excess weight of $73.2 \%, 91.8 \%$, and $91.0 \%$ respectively out of the total study participants and there was no significant difference among the stratified study participants. The significantly high excess weight gain of most postmenopausal women reported by Al-Safi and Polotsky (2015) is not comparable with the higher proportion for BMI, WHtR and WHR in the present study.

The disparity of prevalence rates of obesity and excess weight gain among participants in this study compared to other studies may be associated with age difference. The mean age of the study participants was $60.09 \pm 6.24$ years which was slightly higher than the mean age $(57.25$ \pm 0.80 ) of participants in the study conducted by Arthur et al. (2013). The increase in waist circumference (WC), especially during the postmenopausal stage with age, was largely driven by gains in body weight, but increases in WC have also been reported with ageing in the absence of weight gain (Matthews et al., 2001; Bener et al., 2013). For all the anthropometric measurements, participants' $\leq 50$ years were at a high risk of being obese, although not significantly more than other year groups. Study participants who exceeded more than 15 years of the postmenopausal stage had a high chance of being obese according to their BMI and WHtR but not WHR. This might be explained by a study on lipid changes during the menopause transition in relation to age and weight by Derby et al. (2009). They found that 4.84 years of ageing (mean within-woman age change during the pre- to late-perimenopause transition) along with changes during the transition from pre- to late perimenopause were associated with an exponential weight gain (Derby et al., 2009). Kow et al., (2013) substantiates the claim that physical activity and lean muscle mass naturally decreases with age in women. In postmenopausal women, the body composition changes to more fat and less muscle which 
reduce the rate at which the body metabolises biomolecules and results in weight gain especially central or abdominal obesity culminating in metabolic abnormalities and higher Metabolic Syndrome prevalence (Kow et al., 2013).

BMI and WHR show that postmenopausal women of the Ga tribe were at a higher risk of being obese. This could be influenced by social desirability for overweight and obesity among women in this tribe. A common perception of interest is that being overweight or obese is socially admirable, considered presentable and expected when individuals or families experience improved livelihoods (Nii \& Aryeetey, 2016). This may fuel this growing epidemic of excess weight gain among this tribe. This result resonates with a report by Ofori-Asenso et al. (2016) on the overweight and obesity epidemic in Ghana which recorded that there are high prevalence rates of overweight and obesity in Greater Accra which largely has Gas to be its inhabitants.

Similar to previous studies among Swedish, Brazilian and Iranian women, this study found parity to be the strongest determinant of excess weight gain among postmenopausal women in Ghana. Evidence from the study revealed that participants who had more than seven children are associated with higher risk of excess weight gain. Benkeser et al., (2012) substantiate these findings in a survey by reviewing 2,814 Ghanaian women in Accra Metropolitan area. They established that given birth to 2 or more children was a higher risk for excess weight gain. An increased number of children culturally comes with decreasing physical activity and raised food intake. These may influence the association between excess weight gain and parity.

Although the outcomes of this study are comparable to previous studies, its cross-sectional design makes it unable to establish causality. Non-evaluation of the nutritional status of the participants in the study as part of the determinants of the nutritional state in older age (WHO Organization, 2002) may serve as a study limitation. Also, the female population used in this study may not be representative of the entire postmenopausal women population, given that 
the anthropometric measurements were restricted to women from 45 to 80 years who lived in Ghana for the past three years.

\section{Conclusion}

The postmenopausal Ghanaian women in this study had a high prevalence of excess weight gain which predispose them to a higher risk of chronic cardiovascular diseases, increase in healthcare costs, a decline in quality of life and total wellbeing.

There are several lifestyle and sociocultural factors associated with excess weight gain among postmenopausal women in the country. Most studies are cross-sectional with a limited sample size and covering only certain regions of the country (i.e., not nationally based). In general, comprehensive and in-depth studies on the role of these factors in the occurrence of excess weight gain are lacking. There is a severe shortage of studies related to postmenopusal women with excess weight in African countries. Several factors should be considered when planning for such studies : (1) the questionnaire should include information related to sociocultural factors, lifestyle and physical activity levels, (2) explore current weight management practices among postmenopausal women.

State-funded active healthcare programmes incorporating indigenous physical activities like 'ampe' in Ghana is recommended as interventions and future investigations. 


\section{Declarations}

\section{Ethical clearance}

Ethical approval for this study was obtained from the Human Research Ethics Committee at the University of the Witwatersrand, South Africa (Ref no. M190467). In Ghana, permission was also obtained from the Committee on Human Research, Publication and Ethics of Kwame Nkrumah University of Science and Technology, Kumasi (Ref No. 596/19). Participation was voluntary and written informed consent was obtained from each participant according to the Helsinki declaration.

\section{Consent for publication}

Not applicable

\section{Availability of data and materials}

The datasets sanalysed during the current study are available from the corresponding author on reasonable request.

\section{Competing interests}

The authors declared no conflict of interest

\section{Funding}

None

\section{Authors' contributions}

All authors worked closely together to plan and execute the study. IMB, conceived the study, data collection, data analysis and prepared the manuscript, HM and CB supervised study design and study tools, analyzed data. MMO and TAA participated in coordination and helped literature search. All authors read and approved the final manuscript.

\section{Acknowledgements}

The authors' profound gratitude goes to women in Techiman South and North constituency who volunteered and cheerfully participated in the study. We are also grateful to the leaders of churches and mosques and municipal health director in Techiman for their assistance. 


\section{References}

1. Teede H, Lombard C, Deeks A. Obesity, metabolic complications and the menopause: an opportunity for prevention. Climacteric. 2010;13(3):203-9.

2. Lau DC, Douketis JD, Morrison KM, Hramiak IM, Sharma AM, Ur E. 2006 Canadian clinical practice guidelines on the management and prevention of obesity in adults and children [summary]. Cmaj. 2007;176(8):S1-S13.

3. Blüher M. Obesity: global epidemiology and pathogenesis. Nature Reviews Endocrinology. 2019;15(5):288.

4. Wang YC, Colditz GA, Kuntz KM. Forecasting the obesity epidemic in the aging US population. Obesity. 2007;15(11):2855-65.

5. Dubnov-Raz G, Pines A, Berry E. Diet and lifestyle in managing postmenopausal obesity. Climacteric. 2007;10(sup2):38-41.

6. Flegal KM, Carroll MD, Ogden CL, Curtin LR. Prevalence and trends in obesity among US adults, 1999-2008. Jama. 2010;303(3):235-41.

7. GSS G. Ghana statistical service (GSS), Ghana health service (GHS), and ICF macro. Accra: Ghana Demogr Health Surv. 2009;2008:79-96.

8. Douchi T, Kosha S, Uto H, Oki T, Nakae M, Yoshimitsu N, et al. Precedence of bone loss over changes in body composition and body fat distribution within a few years after menopause. Maturitas. 2003;46(2):133-8.

9. Sowers M, Zheng H, Tomey K, Karvonen-Gutierrez C, Jannausch M, Li X, et al. Changes in body composition in women over six years at midlife: ovarian and chronological aging. The Journal of Clinical Endocrinology \& Metabolism. 2007;92(3):895-901.

10. Lizcano F, Guzmán G. Estrogen deficiency and the origin of obesity during menopause. BioMed research international. 2014;2014.

11. Cuadros JL, Fernández-Alonso AM, Cuadros ÁM, Chedraui P, Pérez-López FR. Body mass index and its correlation to metabolic and hormone parameters in postmenopausal Spanish women. Gynecological Endocrinology. 2011;27(9):678-84.

12. Rodríguez MCN, Santana PS, de Pablos Velasco P, González NS, de Miguel Ruiz E, Medina RC, et al. Estilo de vida, nivel socioeconomico y morbilidad en mujeres posmenopausicas con obesidad de grados II y III. Endocrinología y Nutrición. 2009;56(5):227-32.

13. Ikram MA, Brusselle GG, Murad SD, van Duijn CM, Franco OH, Goedegebure A, et al. The Rotterdam Study: 2018 update on objectives, design and main results. European journal of epidemiology. 2017;32(9):807-50.

14. Gortmaker SL, Swinburn BA, Levy D, Carter R, Mabry PL, Finegood DT, et al. Changing the future of obesity: science, policy, and action. The Lancet. 2011;378(9793):838-47.

15. Charan J, Biswas T. How to calculate sample size for different study designs in medical research? Indian journal of psychological medicine. 2013;35(2):121.

16. Graziottin A. Menopause and sexuality: key issues in premature menopause and beyond. Annals of the New York Academy of Sciences. 2010;1205(1):254-61.

17. Kozakowski J, Gietka-Czernel M, Leszczyńska D, Majos A. Obesity in menopauseour negligence or an unfortunate inevitability? Przeglad menopauzalny= Menopause review. 2017;16(2):61. 
18. Gravena AA, Brischiliari SC, Lopes TC, Agnolo CM, Carvalho MD, Pelloso SM. Excess weight and abdominal obesity in postmenopausal Brazilian women: a population-based study. BMC women's health. 2013;13(1):46.

19. Stevens J, Katz EG, Huxley RR. Associations between gender, age and waist circumference. European journal of clinical nutrition. 2010;64(1):6-15.

20. Arthur FKN, Adu-Frimpong M, Osei-Yeboah J, Mensah FO, Owusu L. The prevalence of metabolic syndrome and its predominant components among pre-and postmenopausal Ghanaian women. BMC research notes. 2013;6(1):446.

21. Cao Q, Yu S, Xiong W, Li Y, Li H, Li J, et al. Waist-hip ratio as a predictor of myocardial infarction risk: A systematic review and meta-analysis. Medicine. 2018;97(30).

22. Kissebah A. Krakower GR. Regional adiposity and morbidity Physiol Rev. 1994;74:761-811.

23. Al-Safi ZA, Polotsky AJ. Obesity and menopause. Best Practice \& Research Clinical Obstetrics \& Gynaecology. 2015;29(4):548-53.

24. Bener A, Yousafzai MT, Darwish S, Al-Hamaq AO, Nasralla EA, Abdul-Ghani M. Obesity index that better predict metabolic syndrome: body mass index, waist circumference, waist hip ratio, or waist height ratio. Journal of obesity. 2013;2013.

25. Matthews KA, Abrams B, Crawford S, Miles T, Neer R, Powell L, et al. Body mass index in mid-life women: relative influence of menopause, hormone use, and ethnicity. International journal of obesity. 2001;25(6):863-73.

26. Derby CA, Crawford SL, Pasternak RC, Sowers M, Sternfeld B, Matthews KA. Lipid changes during the menopause transition in relation to age and weight: the Study of Women's Health Across the Nation. American journal of epidemiology. 2009;169(11):1352-61.

27. Aryeetey RNO. Perceptions and experiences of overweight among women in the Ga East District, Ghana. Frontiers in nutrition. 2016;3:13.

28. Ofori-Asenso R, Agyeman AA, Laar A, Boateng D. Overweight and obesity epidemic in Ghana-a systematic review and meta-analysis. BMC Public Health. 2016;16(1):1239.

29. World Health Organisation. The world health report 2002: reducing risks, promoting healthy life. Geneva: World Health Organisation; 2002.

30. Agbeko, M. P., Akwasi, K., Andrews, D. A., \& Gifty, O. B. (2013). Predictors of Overweight and Obesity Among Women in Ghana. 72-81.

31. States, U., Flegal, K. M., \& Ph, D. (2015). Prevalence of Obesity Among Adults and Youth : (219), 2011-2014.

32. Fouque D, Vennegoor M, ter Wee P, Wanner C, Basci A, Canaud B, et al. EBPG guideline on nutrition. Nephrol Dial Transplant. 2007;22(Suppl 2):ii45-ii87 


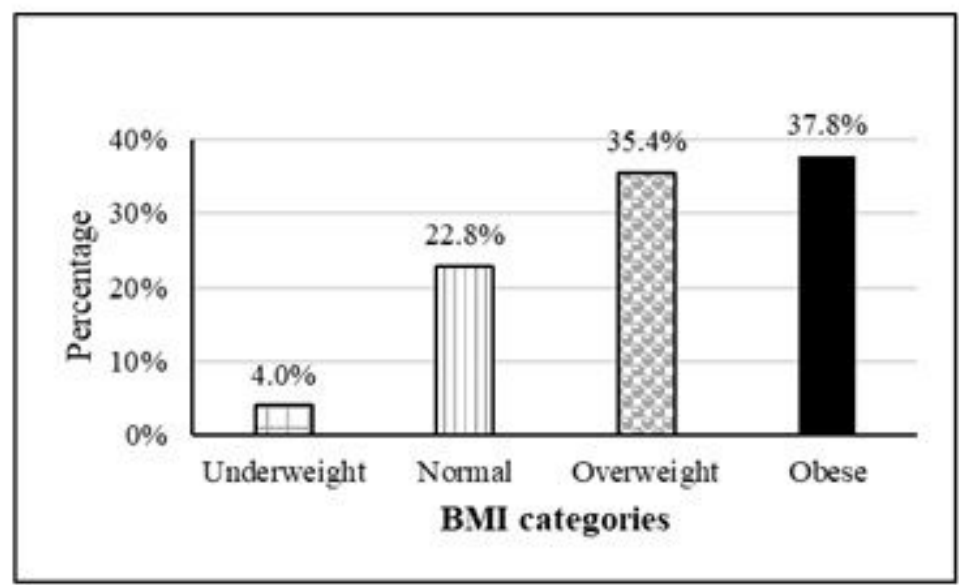

A

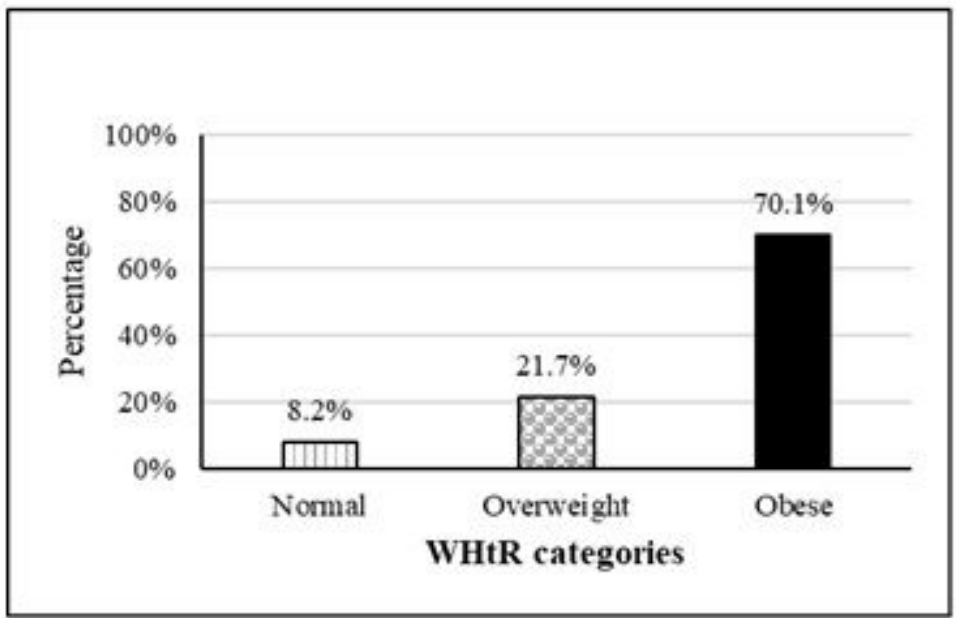

B

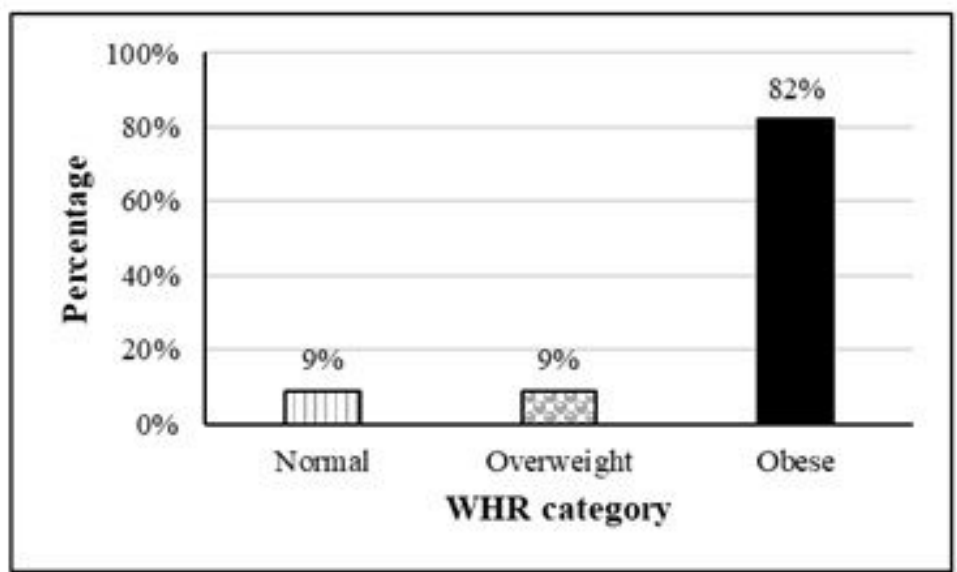

Figure 1

Prevalence of excess weight gain among study participants stratified by; A) body mass index categories, B) waist-to-height ratio categories, C) waist-to-hip ratio categories. 
b)
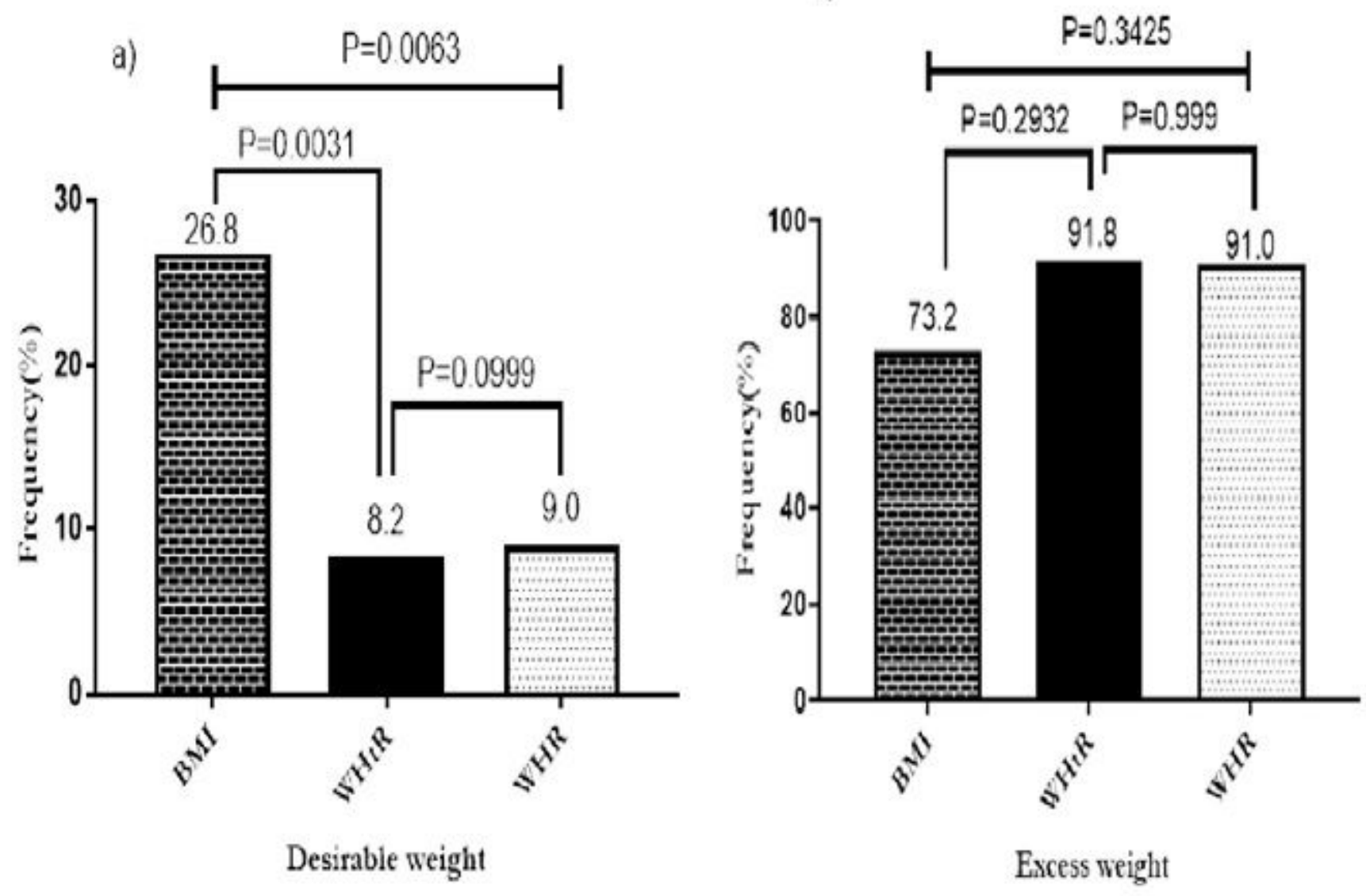

Figure 2

Distribution of body mass index, waist-to-height ratio, and waist-to-hip ratio by desirable and excess weight. 